\title{
EUCLIDES DA CUNHA Y MARIO VARGAS LLOSA: MEDITACIONES INTERTEXTUALES
}

POR

ALFRED MAC ADAM

University of Virginia

La relación entre la novela de Mario Vargas Llosa La guerra del fin del mundo $(1981)^{1}$ y la historia de la sublevación de los discípulos de Antonio Vicente Mendes Maciel -Antonio Conselheiro- contra la República brasileña (1896-1897), escrita por Euclides da Cunha, Os sertões $(1902)^{2}$, puede reducirse (por el absurdo) a un caso de causa y efecto. Es decir, Vargas Llosa trata el mismo asunto que Euclides da Cunha, y Os sertões es un monumento tan imposible de ignorar que es inevitable no sólo asociar los dos libros, sino concluir que sin el libro de Euclides da Cunha el libro de Vargas Llosa no puede existir. Esto es un hecho. Pero, como ocurre tantas veces con los hechos, no significan nada en sí y exigen una interpretación. Para formular una interpretación habría que crear un contexto que incluyera no sólo el hecho de que existen los libros de Vargas Llosa y Euclides da Cunha, sino que explicara la relación intertextual.

Los ensayos de Borges «Las versiones homéricas», incluidos en el volumen Discusión (1932), y «Kafka y sus precursores», de la colección Otras inquisiciones (1951), pueden proveer un marco intelectual para la creación de este contexto. A las ideas de Borges podríamos añadir las de Jonathan Culler sobre la intertextualidad, en particular esta declaración:

Así, la intertextualidad resulta menos un nombre para la relación de una obra con textos anteriores específicos que una designación para su participación en el espacio discursivo de una cultura: la relación entre un texto y los varios lenguajes o las prácticas de una cultura y

\footnotetext{
' Mario Vargas Llosa, La guerra del fin del mundo (Barcelona: Plaza y Janés, 1981). Todas las citas son de esta edición.

${ }^{2}$ Euclides da Cunha, Os sertões, en Obra completa, ed. por Afrânio Coutinho (Rio de Janeiro: José Aguilar Editôra, 1966). Todas las citas son de esta edición.
} 
su relación con aquellos textos que articulan para él (el texto) las posibilidades de aquella cultura ${ }^{3}$.

La intertextualidad, tal como Culler la concibe, es la cuestión más importante para la lectura comparativa de los libros de Vargas Llosa y Euclides da Cunha, pero las idiosincrasias de la cultura latinoamericana muestran las insuficiencias de su definición. Volviendo a Borges veremos por qué.

"Las versiones homéricas» es un ensayo curioso porque trata -en español- las muchas traducciones de Homero al inglés, desde Chapman hasta Butcher y Lang. Borges se jacta de su ignorancia «oportuna» del griego - esto le permite considerar las traducciones sin prejuicios- y luego examina las «versiones» hasta concluir que no hay manera de saber cuál de las traducciones sea la mejor, la más fiel al original, cuál de los «Homeros» sea, en efecto, el más homérico. La idea de que las traducciones sucesivas constituyen un acercamiento a la perfección es otra idea que Borges destruye, señalando que el concepto de «texto definitivo» sólo pertenece a la religión o la fatiga, es decir, a una teoría canónica de la textualidad o a las energías menguantes de la persona que trata de resolver el problema. Aunque sepamos griego, no podemos nunca, sugiere Borges, «leer» el original; sólo podemos leer lo que nuestra tradición, nuestra formación y nuestra imaginación nos permiten leer.

«Kafka y sus precursores» puede leerse como una continuación de «Las versiones homéricas» en el sentido de que define al lector como el que determina el significado literario. Cuando Borges sugiere que los autores crean sus precursores, quiere decir que el lector sensible a ciertos elementos en el texto que lee puede encontrar semejanzas entre aquellos èlementos y otros que cree análogos en textos o anteriores o que ha leído anteriormente. Si tomamos estos dos ensayos como meditaciones sobre el lector como (modificando ligeramente a Valéry) productor y consumidor de literatura, entonces vemos que Borges considera a la traducción como una alegoría de la lectura (y de la escritura) y al lector como creador de una tradición literaria que trasciende la cronología, una tradición sincrónica en que la totalidad queda modificada por cada texto añadido. Así, Borges postula una tradición fluctuante que la formación académica corrige: aunque, por ejemplo, un lector haya leído primero a Virgilio, la historia literaria le enseña que Homero es anterior. Su idea de lo que es la poesía épica puede resultar del orden en que lee -así Virgilio siempre

\footnotetext{
3 Jonathan Culler, "Presupposition and Intertextuality», en The Pursuit of Signs (Ithaca: Cornell Univ. Press, 1981), p. 103.
} 
podrá ser el «original» para él- y sólo la educación puede corregir aquella idea.

Como lectores de La guerra del fin del mundo nos encontramos con un dilema: ¿por qué se interesa este escritor peruano, cuyos libros, de una u otra manera, tratan del Perú y de los peruanos, por una sublevación que ocurrió en el sertón bahiano del nordeste brasileño en el siglo pasado? No es difícil encontrar afinidades temáticas entre éste y los textos más tempranos de Vargas Llosa: los vestigios (o la nostalgia) de epopeyas militares y religiosas están presentes en su obra, siempre cubiertos por un velo de ironía, siempre relegados a un pasado mitológico, como el pasado de la novela de caballerías; por ejemplo, de Tirante el Blanco. «Necesito un héroe», brama el narrador de Byron en Don Juan (otra aventura intertextual); lo mismo pudo haber dicho Mario Vargas Llosa. Pero en vez de encontrarlo entre los personajes de otras obras (como hizo Byron), lo localizó entre los autores mismos ${ }^{3}$. El héroe de La guerra del fin del mundo no es Antonio Conselheiro, sino Euclides da Cunha, autor de $O s$ sertões.

La idea no es tan inverosímil como puede parecer a primera vista. Después de todo, la composición de Os sertões fue un acto heroico, un esfuerzo titánico de encontrar en un hecho histórico menor todas sus causas: geológicas, geográficas, raciales y políticas. Euclides da Cunha tenía todos los materiales necesarios para una epopeya, pero sólo podía escribir en la forma que él y su siglo tenían para decir lo que tenía que decir: la historia. Lo mismo ocurrió con Thomas Carlyle cuando escribió su historia de la Revolución francesa: «La 'ira destructiva' del Sansculottismo: es de esto que hablamos, ya que desgraciadamente carecemos de voz para cantar» ${ }^{4}$. Así describe Carlyle su empresa en el sexto libro de su La Revolución francesa: una historia (1837). Carlyle parodia el primer verso de la Ilíada para mostrar el triunfo del historiador sobre el poeta épico en el siglo xrx: ya los historiadores han vencido a Aristóteles y la historia es superior a la poesía. Pero el estilo de Carlyle como historiador nos interesa como lectores de Euclides da Cunha precisamente porque en su libro, Carlyle crea una narrativa histórica que está saturada de elementos épicos y dramáticos. A diferencia de los novelistas, Tolstoi, por ejemplo, Carlyle no pretende crear personajes ficticios: se queda dentro del marco de la historia documental, pero trabaja con aquellos materiales para crear un texto histórico que hace al lector creerse espectador de las acciones narradas.

${ }^{4}$ Thomas Carlyle, The French Revolution: a History (New York: Modern Library, 1934), p. 167. 
Esta técnica rapsódica de la historiografía aparece en Hispanoamérica en el texto que claramente sirvió como modelo para Os sertões, Civilización y barbarie, vida de don Facundo Quiroga (1845). El Facundo de Sarmiento es otro "precursor» para La guerra del fin del mundo, en particular porque enfatiza la relación entre el autor y el texto, la idea de que la escritura de un libro es una lucha de proporciones heroicas. Nominalmente, Facundo es la biografía del caudillo Facundo Quiroga, uno de los tantos rivales temporarios de Juan Manuel de Rosas. Para explicar a Facundo, Sarmiento, siguiendo el pensamiento positivista, lo trata como un efecto, un fenómeno histórico, algo más allá de la persona Facundo Quiroga. Las causas para un hecho como Facundo, como las causas para Antonio Conselheiro en $O s$ sertões, se encuentran en la geografía, el clima y en las mezclas raciales que produjeron el tipo gaucho en la Argentina. Al parecer, habría muy poco espacio en un libro de esa índole para el autor, en particular para un autor ansioso de hablar de sí mismo, pero tuna lectura de Facundo desmiente esta noción. Sarmiento es una presencia ubicua en su libro, en particular al principio, donde declama en una especie de incantación que se propone evocar el espíritu de Facundo para explicar la situación actual de la nación argentina, como la invocación a la musa en la poesía épica es el modo por el cual el poeta llama la atención sobre sí mismo y sus poderes poéticos. La invocación de Sarmiento del espíritu de Facundo es la invocación de su propio genio. Así, Facundo se transforma en un aspecto del mismo Sarmiento, un nexo con un mundo que admira y que, sin embargo, quiere destruir.

Euclides da Cunha utiliza el libro de Sarmiento como modelo: él también empieza por la naturaleza, con un análisis detallado del pasado geológico del altiplano del nordeste brasileño, el escenario de la guerra de Canudos; luego describe las condiciones actuales de la zona, sus ciclos de sequía, su flora, su fauna. Así fija el escenario (el clisé es importante si pensamos, junto con Víctor Turner ${ }^{5}$, en los dramas sociales como verdaderos dramas) para una descripción del habitante del sertón, el resultado de la fusión de negros, indios y portugueses. Las metáforas de Euclides da Cunha, en general, describen la tierra y el hombre en relación al sufrimiento, a la lucha y a la muerte. Concluye su presentación de la tierra con estas observaciones:

O martírio do homem, ali, é o reflexo de tortura maior, mais ampla, abrangendo a economia geral de Vida. Nasce do martírio secular da Terra...

${ }^{5} \mathrm{Me}$ refiero aquí al capitulo «Social Dramas and Stories About Them», en From Ritual to Theatre: the Human Seriousness of Play (New York: Performing Arts Journal Publications, 1982). 
Esta es una variación desesperada del darwinismo, una visión del mundo en que la lucha es la ley universal, donde la batalla de todos contra todos incluye hasta el sol en el cielo.

Es aquí donde Euclides difiere mucho de Sarmiento. Advertimos la admiración de Sarmiento hacia los gauchos, hasta cuando pide su exterminación; exterminio que sería un acto de voluntad, no el resultado de un proceso histórico. Euclides da Cunha ve la historia, natural y humana, como un fluir predeterminado; se reconoce esto en sus declaraciones sobre el futuro de la gente mestiza del nordeste en su prólogo:

Primeiros efeitos de variados cruzamentos, destinavam-se talvez à formação dos principios imediatos de uma grande raça. Faltou-lhes, porém, uma situação de parada, o equilíbrio, que lhes não permite mais a velocidade adquirida pela marcha dos povos neste século. Retardatários hoje, amanhã se extinguirão de todo.

A civilização avançará nos sertões impelida por essa implacável «fôrça motriz da História» que Gumplowicz, maior de que Hobbes, lobrigou, num lance genial, no esmagamento inevitável das raças fracas pelas raças fortes (p. 93).

La lucha por Canudos fue para Euclides da Cunha un crimen que él se vio obligado a denunciar (p. 94) porque los brasileños, políticamente exaltados, destruían lo que él llamaba «a rocha viva da nossa raça» (p. 479). Canudos fue una combinación grotesca: el martirio (Antonio Conselheiro y sus discípulos morían por su fe), el sacrificio (los fanáticos de la República exigían el sacrificio de estos locos al altar republicano) y el suicidio (la nación se mataba). Canudos, para Euclides da Cunha, es Troya, y él es su Homero.

A diferencia de Homero - a diferencia también de Sarmiento y Vargas Llosa-, Euclides da Cunha fue un testigo (o testigo parcial) de las acciones que describe. Esta diferencia lo asemeja a Bernal Díaz del Castillo o a Ercilla, o como a nuestros corresponsales de guerra, Michael Herr (por ejemplo), autor de Dispatches, crónica de la guerra de Vietnam. Esta idea del escritor-testigo parece haber impresionado a Vargas Llosa, pues el personaje que crea que más se parece a Euclides da Cunha es el periodista miope, asmático, que acompaña a la malhadada expedición de Moreira César a Canudos a fines de febrero de 1897, que pasa por las líneas y vive los últimos cuatro meses de la campaña (desde junio hasta los primeros días de octubre de 1897) en Canudos. Vargas Llosa añade el toque irónico de hacer que su periodista -que en el libro no tiene nombre- rompa sus anteojos de manera que durante su estancia en Canudos está casi totalmente ciego, digno rito de pasaje para el hombre que jura 
(p. 341) que escribirá sobre Canudos para decir la verdad y, más importante, para ver que la memoria de la guerra no desaparezca en el olvido.

Vargas Llosa establece una jerarquía de artistas verbales en La guerra del fin del mundo. Es periodista (feo, torpe de modales, de voz desagradable), que está a punto de renacer como historiador-épico, es el ápice de la estructura. Más abajo está el deformado León de Natuba, cronista o evangelista de Antonio Conselheiro que escribe - para «eternalizarlas» (el verbo es suyo, p. 456) - cada palabra que pronuncia el Profeta. En el escalón inferior, también deformado, también monstruoso, también un desterrado, es el Enano de circo que mantiene vivo al periodista en Canudos. Lo hace recitando los fragmentos de epopeyas y romances (los cuentos sobre los Caballeros de la Mesa Redonda, los Doce Pares de Francia y otros) que son parte de la tradición oral del sertón (véanse páginas 338 y 350). Así, la epopeya escrita y el bardo-historiador-escritor se apoyan, por un lado, en una tradición oral (derivada de una tradición escrita decaída) y, por otro, en una tradición de obras que funden la hagiografía, las vidas de santos, las vidas de héroes, la conservación de las palabras de un santo-caudillo por uno de sus discípulos.

Pero la redacción de hechos heroicos es sólo un aspecto de la actividad que forma la identidad del escritor épico-histórico. Para todos estos escritores, desde Carlyle y Sarmiento en adelante, su empresa es en sí una lucha, el acto de composición es una batalla y la victoria ocurre en el momento en que terminan el texto. Es como si hubiera una epopeya paralela para los escritores; es decir, si tomamos en serio lo que dice Euclides da Cunha, si decimos que la campaña de Canudos puede entenderse como una epopeya de lucha (Strife epic) ${ }^{6}$, podemos también afirmar que hay incluida en el texto una epopeya de búsqueda (Quest-epic) cuyo protagonista es el artista. Así, la guerra entre los discípulos de Antonio Conselheiro y la República Brasileña termina en la destrucción de una ciudad, mientras que la búsqueda del artista le lleva primero al estudio y luego a la sabiduría, la sabiduría que le permite contemplar la acción como una totalidad, que le permite presentar aquella totalidad de un texto coherente, estéticamente satisfactorio. Mario Vargas Llosa está consciente de la existencia de este patrón y hace que su periodista pase por todas las etapas: primero es el periodista cínico, un parásito; luego es el espectador-sufridor, ciego partícipe en el hedor y el terror de la guerra. Al final es el sobreviviente iluminado juntando su información, preparándose para escribir.

${ }^{6}$ Estas ideas sobre la epopeya son del profesor James C. Nohrnberg y aparecen en sus ensayos inéditos sobre Milton. Quisiera agradecer al profesor Nohrnberg por haberme permitido leer sus estudios. 
Mario Vargas Llosa no es el único escritor sobre la guerra de Canudos que ha observado esta lucha épica del artista. En 1920, el escritor escocés Robert Bontine Cunninghame Graham, amigo de Joseph Conrad y experto en asuntos hispanoamericanos, publicó un libro titulado $\mathrm{A} \mathrm{Bra-}$ zilian Mystic, Being the Life and Miracles of Antonio Conselheiro ${ }^{7}$. Cunninghame Graham dice en su prefacio que fue Teddy Roosevelt mismo quien le sugirió el tema del sertón brasileño, pero queda muy claro que después de leer el libro de Euclides da Cunha no pudo resistir la tentación de escribir sobre Canudos. Fue sin duda porque Canudos se parece tanto a los Highlands escoceses, y el fervor religioso de Antonio Conselheiro se parece tanto a la fe de hierro de los Cameronians. También Walter Scott (el de Waverley, Old Mortality y Rob Roy) influye en la percepción de Cunninghame Graham de Canudos. Pero lo que llama la atención en Un místico brasileño es el sentido de misión que poseía el autor. Como dice el prefacio:

Este libro está fatalmente encaminado, y llegará muy pronto a las librerías de viejo, para ser vendido allí junto con otras gangas por un penique... porque trata de gente desconocida y de una vida desconocida y ni sospechada por el vulgo. No importa, porque el que escribe un libro escribe para darse a sí mismo un placer particular y si no es así, sería mejor que no escribiera. // Es inevitable que mi versión del místico yagunço quede pudriéndose en la lluvia en un estante, y está bien. Tostarse al sol o pudrirse en la lluvia, me da lo mismo. La lucha misma es lo que más vale en la lucha, y el resultado es algo secundario; de la misma manera, es la escritura de un libro lo que le importa al escritor, porque en la escritura él ha tenido su lucha (pp. XI$\mathrm{XII})$.

Esta es, indudablemente, una declaración melodramática, pero la idea de que la escritura de un texto sobre la guerra es también una guerra es una imagen que merece nuestra atención. Vargas Llosa se fijó en ella y también en el resto del pastiche brillante que hizo Cunninghame Graham de Euclides da Cunha. Leemos en Un místico brasileño: "La ley del Emperador tenía tan poca fuerza en el Sertón como la del Rey más allá del paso de Aberfoyle en los días de Rob Roy» (p. 48). Leemos en La guerra del fin del mundo los pensamientos de Galileo Gall, un anarquista-frenólogo que está tratando de llegar a Canudos: «La República tiene tan poca fuerza en Bahía como el Rey de Inglaterra más allá del Paso de Aberfoyle,

${ }^{7}$ Robert B. Cunninghame Graham, A Brazilian Mystic, Being the Life and Miracles of Antonio Conselheiro (New York: Books for Libraries Press, 1971). 
en los días de Rob Roy McGregor» (p. 74). Esta no es una coincidencia; y el hecho de que Galileo Gall es escocés puede ser, como la frase reescrita, una suerte de homenaje a Cunninghame Graham.

Nos olvidamos que los escritores son también lectores, y que es el acto de leer el que crea tanto el significado del texto como los precursores de los textos que leemos. El significado de La guerra del fin del mundo no está en Cunninghame Graham y Euclides da Cunha (aunque nos permite ver que lo que afirma Jonathan Culler sobre la relación entre un texto y una cultura sencillamente no funciona para la literatura latinoamericana). Incluye a Sarmiento $y$, como precursor remoto, a Thomas Carlyle, y a Mario Vargas Llosa mismo, espectador de un siglo de guerra continua, tanto civil como internacional. A diferencia del narrador de Byron, Vargas Llosa no necesitaba un héroe: necesitaba una lucha, «Una Gran Calamidad Histórica, o Choque de Pueblos», como la llama Thomas. Hardy en The Dynasts (1903-08), y encontró la lucha que necesitaba en Os sertões, el choque de pueblos y la lucha del escritor para dominar su tema. Fue una guerra que no decidió nada, que no alteró en nada la historia: fue una guerra cuya única justificación serían los libros que se han. escrito para inmortalizarla. 